\title{
Ouro Preto de todos os tempos: sentidos e efeitos do patrimônio na condição histórica da cidade
}

\author{
Ouro Preto of all time: the meanings \\ and effects on historic heritage city status
}

Rosiane Ribeiro Bechler*

Júnia Sales Pereira**

\section{RESUMo}

Dentre os demais estados, Minas Gerais é um dos que confere ao Brasil substância de seu passado colonial, singularizando e eternizando-se através das políticas de patrimônio e de um discurso fundador do Estado que faz coincidir o período aurífero ao passado requerido pela nação. A cidade de Ouro Preto consolidou-se como o cenário histórico ideal conferindo conteúdo suntuoso ao passado histórico da ex-colônia, em um movimento pela história que a legitima como raiz e como memória. $\mathrm{O}$ artigo problematiza alguns dos efeitos da patrimonialização, em especial aqueles advindos da singularização desse cenário do barroco mineiro como substrato do histórico, o que configura o silenciamento de outras tantas histórias e memórias que também compõem a história dessa cidade. Considerando, evidentemente, a importância das políticas públicas de

\section{Abstract}

Among the others states, Minas Gerais is the one that gives to Brazil purport of its colonial past, eternalizing and singling itself across heritage policies and a founder speech of State, making coincide of auriferous period with required past by the nation. The Ouro Preto City was consolidated as an ideal historical scenery conferring its sumptuous content of the historical past of former colony, in one movement by history which legitimates with memory and root. This article aims to discuss the problematization of some of the patrimonialization's effect, in special those arising effects of the singling. This mineiro baroque scenery as historical substrate, what in silencing of many others memories and histories, composes the history of this city. In concerning, obviously, of the importance of heritage public policies, we intend to reflect about the result of the directions in

\footnotetext{
* Mestre em Educação pela UFMG, doutoranda em Educação pela Universidade do Estado de Santa Catarina (UDESC). rosiribeirobechler@gmail.com

** Doutora em História, Universidade Federal de Minas Gerais (UFMG); Ministério da Educação. juniasales@gmail.com
} 
patrimonialização, interessa-nos provocar reflexões sobre os seus efeitos de sentido em aulas de história, evidenciando escalas possíveis para compreensão e alargamento dos horizontes de interpretação deste espaço múltiplo que é o de uma cidade "histórica", patrimônio da humanidade e ícone referencial do passado histórico do Brasil.

Palavras-chave: ensino de História; patrimônio histórico-cultural; jogos de escalas; história da cidade. the history classes, showing possible scales to comprehension and enlargement of interpretation horizons about this multiple space that is of one "historical" city, humanity heritage and referential icon of historical past of Brazil.

Keywords: History teaching; historical and cultural heritage; scales games; city history.

Assim como os demais estados brasileiros, Minas Gerais formou-se em um processo histórico complexo e desencadeado por múltiplos fatores, no bojo das especificidades políticas, econômicas e socioculturais advindas de um passado colonialista, dos quais ainda na atualidade sentimos os reflexos. No entanto, parece-nos que a elaboração de uma formação histórica assentada na descoberta do ouro e das pedras preciosas conferiria a Minas Gerais um caráter singular, servindo de condição para tornar equivalentes essa história regional e a história brasileira no que se refere ao passado colonial ou, no mais tardar, para tornar indissociáveis a história colonial e a história das Minas do Ouro.

Por meio de operação simbólica, Minas confere ao Brasil a substância de seu passado colonial, singularizando e eternizando-se através das políticas de patrimônio e de um discurso fundador do Estado que faz coincidir o período aurífero ao passado requerido pela nação a partir de seu presente, do regime de historicidade no qual se inscreve (Hartog, 2006). Nesse sentido, a escolha da descoberta das riquezas minerais, sobretudo auríferas, como ponto de partida da formação histórica de Minas Gerais serve ainda hoje de substrato para justificar determinadas posturas e justificativas em relação às políticas de patrimonialização, orientando em especial a escolha de elementos culturais e de memórias datadas nesse período como referentes à gente mineira e à sua pressuposta condição identitária historicamente demarcada.

Conforme Hartog,

O século XX é o que mais invocou o futuro, o que mais construiu e massacrou em seu nome, o que levou mais longe a produção de uma história escrita do ponto de 
vista do futuro, conforme aos postulados do regime moderno de historicidade. Mas, ele é também o século que, sobretudo no seu último terço, deu extensão maior à categoria do presente: um presente massivo, invasor, onipresente, que não tem outro horizonte além dele mesmo, fabricando o passado e o futuro do qual ele tem necessidade. Um presente já passado antes de ter completamente chegado. Mas desde o fim dos anos 1960, este presente se descobriu inquieto, em busca de raízes, obcecado com a memória. (Hartog, 2006, p.270)

Nessa perspectiva, podemos dizer que Ouro Preto consolidou-se como o cenário histórico ideal conferindo conteúdo suntuoso ao passado histórico da ex-colônia, em um movimento pela história que a legitima como raiz e como memória. A cidade histórica foi declarada em 1933 Patrimônio Nacional pelo Instituto do Patrimônio Histórico e Artístico Nacional, no bojo das políticas estado-novistas em busca de definições por uma identidade nacional, e em 1980 declarada Patrimônio Cultural da Humanidade pela Unesco, no bojo de políticas internacionais que buscavam preservar alguns registros dos avanços desse fenômeno que se acentua no fim do século XX denominado por François Hartog de presentismo. Assim, o reclame ainda atual por uma memória da formação do estado de Minas Gerais assentada na descoberta do ouro em fins do século XVII e início do XVIII, legitima a cidade de Ouro Preto - eleita ante os demais 852 municípios do estado como o epicentro histórico e geográfico da história mineira e, em escala, como relíquia brasileira e da humanidade.

Propomo-nos neste artigo a variar as escalas de observação para problematizar em que medida a patrimonialização, ao promover a singularização desse cenário do barroco mineiro como substrato do histórico, acaba por evidenciar o silenciamento de outras tantas histórias e memórias que também compõem a história de Ouro Preto, de Minas e do Brasil, a exemplo do distrito ouro-pretano de Miguel Burnier, conforme discutiremos mais adiante.

O movimento que aqui se apresenta, portanto, diz respeito à delicada confecção dos contornos e conteúdos que informam a condição histórica do registro patrimonial, supondo serem eles arbítrios dos processos sociais, dos interesses de cada momento e do agenciamento do passado por razões do presente. 


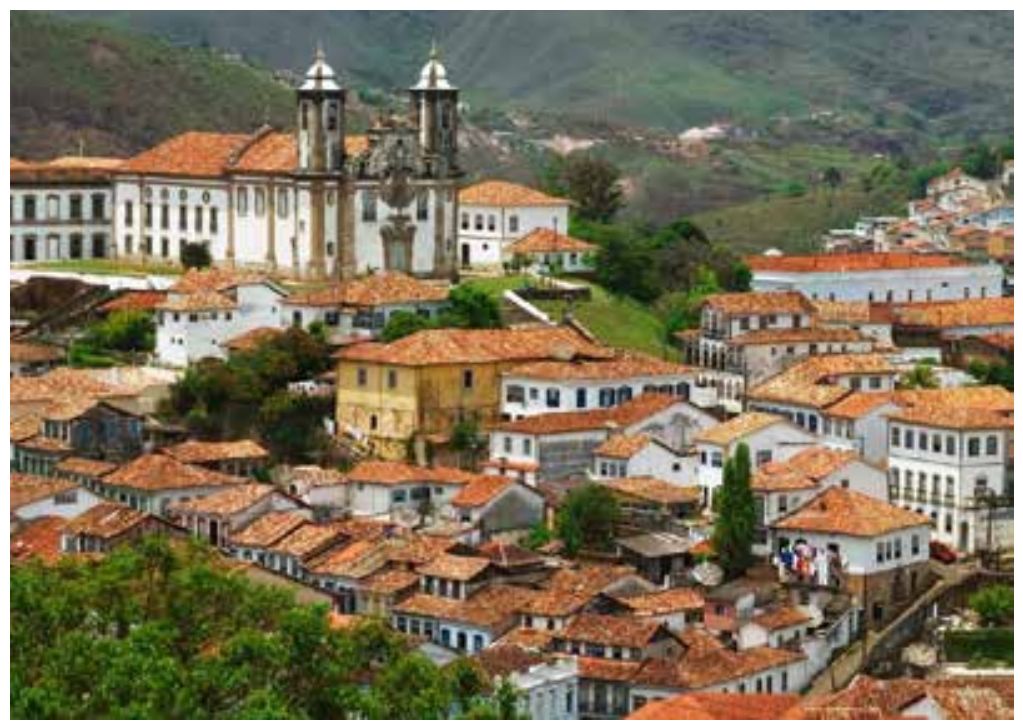

Figura 1 - Visão panorâmica do centro histórico de Ouro Preto

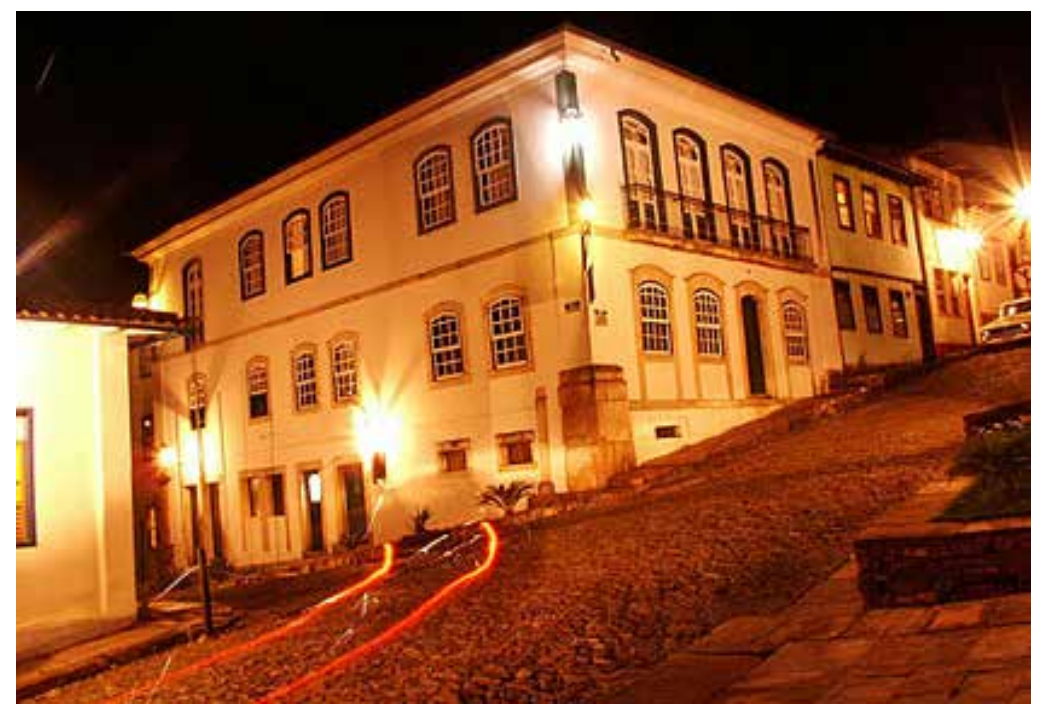

Figura 2 - Detalhe - Centro Histórico de Ouro Preto

Imagens disponíveis em: http://turismo.culturamix.com/nacionais/sudeste/ouro-preto 


\section{Minas Gerais, UMA FORMAÇão HistóRICA EM CENÁRIO IDEAL}

A especificidade da formação histórica de Minas Gerais e o imaginário social que se funda a partir dela foi discutido em profundidade por Maria Arminda Arruda em sua tese de doutorado, no final da década de 1980. Suas reflexões foram posteriormente publicadas no livro A mitologia da mineiridade, em 1990, e ainda hoje se configuram como importantes substratos para discussão acerca da História Regional de Minas Gerais, por apresentar e problematizar "os componentes de um fenômeno que possuiu características de mito e de apalpar o rosto fugidio da identidade cultural" (Arruda, 1990, p.22), no caso a mineiridade.

A autora oferece-nos elementos importantes para compreender as tramas que colocam o tema da Minas Colonial em posição privilegiada tanto na História de Minas Gerais quanto na História do Brasil. Uma posição construída e estabelecida a partir de "uma mescla de gêneros discursivos, manifesta em falas políticas, em livros de memórias, em obras literárias" (Arruda, 1990, p.22), e que se reafirma e é mediada também pelas políticas de patrimonialização observadas no estado.

Considerando a literatura produzida pelos viajantes europeus a Minas Gerais no decorrer do século XIX - no contexto de redescoberta do Brasil inaugurado pela transferência da Corte Portuguesa em 1808 - como uma das fontes do mito (da mineiridade), Maria Arminda Arruda destaca que

A caracterização de Minas Gerais pelos viajantes desponta num quadro eivado por comparações, construído a partir de referências à Europa, como vimos, às outras regiões brasileiras, ou inseridos no conjunto do país. Nos dois primeiros aspectos, o procedimento utilizado para identificação baseia-se no realce das diferenças; já no último sobreleva o critério da integração. Nas primeiras comparações ganham contorno os aspectos regionais, desembocando na construção de um perfil definido dos mineiros. No caso derradeiro, são delineados os traços do caráter nacional, de onde os mineiros são pensados. (Arruda, 1990, p.53)

É nessa perspectiva relacional que são elaboradas ainda no século XIX versões importantes sobre uma história de Minas Gerais inaugurada pela descoberta do ouro, afirmando desde então sua formação particular e mítica: 
No caso das Minas, a fantasia em torno da Terra assumiu a dimensão do sonho concretizado ... Foi o ouro das Minas Gerais que permitiu aos portugueses transformar uma criação mítica em realidade. Através dele puderam os lusitanos recuperar um entre os fios que os conduziam ao paraíso e que foram perdidos nos primeiros séculos do descobrimento. $\mathrm{O}$ achado, não obstante, dá-se após longa demora, encontrando já os portugueses conspurcados pelas imagens do inferno. A descoberta do ouro do século XVII, teve o condão de refazer em parte as visões edênicas. Nesses termos, as minas nasceram diferenciadas do conjunto da colônia. Vieram ao mundo envolvidas pela mística de Midas. Mesmo no futuro, quando o espaço regional estava delimitado, elas continuaram a ser pensadas como o coração a emitir fluxos vitais para o corpo. (Arruda, 1990, p.54-55)

Os viajantes estrangeiros irão considerar em seus relatos desde os traços da paisagem aos efeitos do ouro - riqueza fácil e de pouco esforço - como influências determinantes sobre a índole dos mineiros, constituindo suas características físicas e de caráter, que mais adiante seriam remodeladas para dar origem aos privilegiados traços políticos das elites mineiras (Arruda, 1990). Ainda que no século XIX a atividade mineradora na capitania de Minas Gerais já houvesse entrado em declínio, foi com base nela que os viajantes estrangeiros elaboraram seus relatos, reforçando o papel atribuído aos aspectos econômicos, políticos, sociais, culturais e simbólicos desse evento na História de Minas Gerais e na História do Brasil. Inaugurando a força de uma memória regional fundada e legitimada pela descoberta do ouro, acontecimento a partir do qual, nessa narrativa, todos os demais de desdobram ou a ele se ligam com a força das narrativas.

Força essa que no decorrer do século XIX é apropriada pelas políticas do Império, e no final desse período é renovada pelas demandas republicanas, garantindo a Minas Gerais um lugar de permanência no contexto nacional, com a legitimação mesmo dos reveses de sua História e a acentuação de traços ainda hoje associados à identidade mineira compreendida sob essa égide: $o$ caráter político e o apego à liberdade.

A ênfase no caráter politizado da vida social de Minas, onde "a liberdade vivia na boca de todos" e transpirava pelos poros de seus habitantes, encontra-se presente já nas visões do século XIX. Os viajantes coloriram o vezo político dos mineiros e deram ênfase à sua revolta diante do jugo português... (Arruda, 1990, p.65) 
Assim, na história de Minas Gerais, a distinção do conjunto é acompanhada pelo desejo de integração a ele, sobrepondo-se aos demais contextos regionais na narrativa do nacional. E essa distinção vincula-se à singularidade de suas origens, sinalizando

as transformações que, no conjunto, respondem pela constituição de Minas e dos mineiros em personagens entremeadas numa teia complexa. Profundamente entretecido na sua história, o "espírito de Minas" visita e hospeda a história brasileira ... O imaginário mineiro pronto e elaborado - a mineiridade - que remanesce, por certo no manancial da História de Minas, superpôs ao tempo inerente à vida o seu próprio tempo, esquadrinhando portas alheias. (Arruda, 1990, p.87)

Nesse sentido, a História de Minas Gerais configura-se a partir de um regionalismo particular e distinto daqueles visualizados em outros estados da Federação. Por exemplo, o caso do Rio Grande do Sul, já discutido por Roberto da Matta, ${ }^{1}$ no qual o regionalismo é perpassado de um caráter separatista e isolacionista. Já "Minas está sempre mesclada ao conjunto, ao terreno comum, e as suas mãos de escrivã tentam urdir a História do Brasil” (Arruda, 1990, p.102), num esforço de organização também da própria história, em que

Não deixa de ser curioso que o estado de Minas, provavelmente o mais diferenciado do ponto de vista interno, produza uma visão regional tão integrada. Apenas para exemplificar, a formação das sub-regiões mineiras seguiu um processo de dentro para fora e vice-versa. Na época do ouro imperou a constituição externa; após a decadência, a diáspora mineira partiu do centro para a periferia; no período seguinte, ocorreu uma assimilação das regiões periféricas aos estados contíguos. (Arruda, 1990, p.102)

Assim, a par de sua diversidade interna, o que sobressai ainda na atualidade do discurso sobre Minas e sobre a mineiridade é um encadeamento histórico que elege como marco fundador e de origem a descoberta do ouro, legitimando memórias que, de diferentes formas e por diferentes meios, são perpetuadas sobre a história mineira ou sobre os mineiros. Uma história construída sobre a ideia de uma imagem unitária, revelando as necessidades de junção das disparidades internas (Arruda, 1990, p.103). Por isso que, "diversamente da identidade regional gaúcha que se introverte ... assistimos em Minas ao aparecimento do caráter regional a partir da identificação no 
nacional. A mineiridade diferencia-se ao integrar-se, particulariza-se quando se funde no todo" (p.108).

A mineiridade tem esse quê de impregnação cotidiana. Os traços com os quais delineia e particulariza diferentes manifestações - na culinária, na música, nos falares, nos jeitos, no humor, nas artes cênicas e visuais - renovam-se como temas de pesquisas sempre atuais ${ }^{2}$ e como convocações à diluição da pluralidade expressa pela vida social. Assim, identidade e história se entrelaçam por força das narrativas, conquanto não se confirmem por força das experiências, em cenários que se alteram num jogo de escalas, conforme demandas advindas tanto da esfera nacional quanto das particularidades regionais. Particularidades em sua maioria fundadas no período histórico colonial, e, principalmente, no decorrer do século XVIII. Traços identitários que se perpetuaram ao longo de memórias eleitas e legitimadas também pelas políticas de patrimonialização, que elegem o que devemos "preservar" e proteger das intempéries do tempo e da memória, ao mesmo tempo que solapam, no decurso do tempo, a multiplicidade de experiências no jogo irregular que dispõe lembrança e esquecimento.

Memórias subterrâneas são colocadas assim ao dispor do marco colonial, mas mesmo sob o marco do julgo aurífero, haveria novas escolhas que privilegiariam espaços sociais, históricos e geográficos que se alinham a Ouro Preto (como Mariana, Diamantina e Tiradentes, entre outras) silenciando tantos outros que também lhes são "contemporâneos" (como Antônio Dias, Pedro Leopoldo, Pitangui). Escolhas em cujas sombras revelam silenciamentos, indicando que a admissão contemporânea de que a história não se efetiva sob narrativa única ou de que há memórias e histórias distorcidas, silenciadas ou negadas, não está ainda de fato acompanhada de uma revisão histórica dos marcos canonizados pela literatura didática, pela historiografia, e mais recentemente pelas políticas públicas de patrimonialização, que fizeram costurar a história de Minas Gerais à da colonização portuguesa no bojo da opulência aurífera.

Ouro Preto afirma-se como um cenário histórico ideal, fundamentando a longevidade das marcas do ouro na história de Minas e a configuração de uma suposta identidade mineira, conquanto não exclusiva, que remonta a modos e registros informados pela presença colonial. Esse movimento enseja 
memórias calcadas num passado congelado por meio do patrimônio barroco e dos vestígios de uma vida social orientada pela opulência e pelo traçado da sede da administração em Minas. Trata-se da perpetuação de uma memória compreendida como via fundadora do marco colonial-mineiro, que ao mesmo tempo, em escala macro, concede substância a um determinado projeto de nação e, numa escala micro, concede importância ao passado convenientemente alçado à condição de tesouro da humanidade.

\section{Ouro Preto em escalas: MEMóRIAS Eleitas E ESPAÇOS SILENCIADOS}

Ao pensarmos as relações entre a narrativa histórica, as políticas de patrimonialização e o espaço sócio-histórico de Ouro Preto na perspectiva das escalas nos aproximamos das reflexões propostas pelo historiador Jacques Revel, teórico da Microanálise, acerca do conceito dos jogos de escalas.

A Micro-história aponta para uma nova configuração e dinâmica do processo sócio-histórico, em contraponto a outras perspectivas de estudos desenvolvidos até então. Isso porque tanto a orientação positivista, pautada na ideia de uma possível assepsia na conduta do historiador na produção do conhecimento histórico - este balizado em fatos e feitos políticos e econômicos, quanto à ideia de uma história totalizante divulgada pela Escola dos Annales no decorrer de suas três gerações de estudiosos, continuavam a relegar aos bastidores da trama histórica os personagens da vida cotidiana. A Micro-história surge então como um arcabouço teórico e metodológico a orientar investigações por outros vieses.

Apesar da grande heterogeneidade das produções neste campo, são postulados como a variação das escalas de análise, a problemática do foco sobre os sujeitos que participam da trama histórica e o valor conferido à narrativa $\mathrm{e}$ à capacidade interpretativa do historiador, que definem a Micro-história como campo de produção do saber (Levi, citado em Burke, 1992; Revel, 1998).

Já à Microanálise, vertente francesa dessa escola historiográfica, cujo expoente foi o historiador Jacques Revel, interessa tanto o ajuste do foco sobre uma escala específica quanto um trabalho de contextualização múltipla, compreendendo que 
cada ator histórico participa, de maneira próxima ou distante, de processos - e, portanto, se inscreve em contextos - de dimensões e de níveis variáveis, do mais local ao mais global. Não existe portanto hiato, menos ainda oposição, entre história local e história global. O que a experiência de um indivíduo, de um grupo, de um espaço permite perceber é uma modulação particular da história global. Particular e original, pois o que o ponto de vista micro-histórico oferece à observação não é uma versão atenuada, ou parcial, ou mutilada, de realidades macrossociais: é ... uma versão diferente". (Revel, 1998, p.28, grifos nossos)

Nesta análise historiográfica o contexto micro é compreendido como uma nova forma de modulação que pressupõe a redução da escala de análise como estratégia para apreensão de uma versão diferente da narrativa histórica, mas que carrega em si observações elucidativas de um contexto que é global. Nesse sentido, conforme propõe Revel (1998), não é a oposição entre as narrativas do local e do global que permite visualizar outros vieses do conhecimento histórico, mas o reconhecimento e a compreensão de ambas em uma perspectiva relacional. Perspectiva que se concretiza, no limite, pela atuação dos próprios sujeitos nos variados contextos em que se inserem e transitam.

Por isso, a noção de escalas - originária da Geografia - apropriada pelo historiador Jacques Revel (1998) como fundamentação teórica e metodológica das pesquisas em Microanálise, perpassa reflexões propostas neste texto, que problematiza como as escolhas das políticas de patrimonialização implicam a visualização e compreensão do espaço sócio-histórico a partir de uma escala determinada, num movimento que tanto favorece algumas memórias quanto silencia tantas outras. Revel (1998) afirma que

a escolha de uma escala particular de observação produz efeitos de conhecimento, e pode ser posta a serviço de estratégias de conhecimentos. Variar a objetiva não significa apenas aumentar (ou diminuir) o tamanho do objeto no visor, significa modificar sua forma e sua trama ... Notemos desde já que a dimensão do "micro" não goza, nesse sentido, de nenhum privilégio especial. É o princípio da variação que conta, não a escolha de uma escala em particular. (Revel, 1998, p.20, grifos nossos)

O registro de Ouro Preto como patrimônio em múltiplas escalas, de Minas à humanidade, produz, certamente, efeitos de conhecimento, dispondo 
aos docentes narrativas compostas sob diferentes perspectivas. Essa condição patrimonial máxima certamente dispõe a cidade como ícone do passado brasileiro, conquanto tenha sido preterida como sede do governo de Minas, provocando a enunciação de narrativas não acionadas antes do processo de tombamento e registro, mas com efeitos de longa duração. Há certamente estratégias de conhecimento produzidas nessa operação histórica revelando condições de realização da memória-relíquia da humanidade. Uma dessas estratégias é a evocação ou singularização cada vez mais atual do centro histórico como epicentro "da" história. Retomando Hartog, entendemos que

Daí vem este olhar museológico lançado sobre o que nos cerca. Nós gostaríamos de preparar, a partir de hoje, o museu de amanhã e reunir os arquivos de hoje como se fosse já ontem, tomados que estamos entre a amnésia e a vontade de nada esquecer. Para quem? Para nós, já ... Se o patrimônio é doravante o que define o que nós somos hoje, o movimento de patrimonialização, este imperativo, tomado ele mesmo na aura do dever da memória permanecerá um traço distintivo do momento que nós vivemos ou acabamos de viver: uma certa relação ao presente e uma manifestação do presentismo. (Hartog, 2006, p.271)

O reclame presentista pela preservação de uma memória diz também da angústia dos sujeitos ante um tempo acelerado, que se esvai antes que possa ser apreendido, levando consigo registros de histórias passadas sem, contudo, legar ao presente outras formas de memória. É na contramão dessa aceleração do tempo e de um risco eminente do apagamento de memórias que a patrimonialização tornou-se, em fins do século XX, uma política de alcance internacional, que já demanda debates em torno do que pode ou não ser considerado como patrimônio (Hartog, 2002).

Nesse contexto, ação preservacionista configura-se como uma estratégia constante que se por um lado preserva o cenário histórico da cidade eleita sob imperativo do passado histórico, por outro produz efeitos sobre os viventes em cada época, com especial reverberação sobre a população da cidade de Ouro Preto residente tanto no núcleo patrimonializado quanto fora dele, e, ademais, com efeitos de sentido e de experiência sobre as inúmeras escolas (e seus sujeitos) que a Ouro Preto chegam semanalmente.

Sejam essas narrativas veiculadas por livros didáticos, por programas televisivos ou por materiais de divulgação e turismo sobre a região, a tessitura 
histórica traz como pano de fundo comum a opulência aurífera que remonta ao século XVIII e a traços culturais e identitários que a ela se vinculam, convocando narrativas às aulas de história em que o passado dado a ver por meio do patrimônio define "a" cidade. Nesse sentido, as políticas de patrimonialização que na década de 1980 tornaram até o chão da sede de Ouro Preto Patrimônio da Humanidade acabaram por configurar o cenário histórico, orientando olhares sobre contornos previamente instituídos, de uma cidade que, em escalas, revela-se múltipla e complexa.

Veja-se o exemplo mais recente do interesse dos turistas da Copa do Mundo 2014 em conhecer Ouro Preto - sua sede, não a cidade. Entretanto, esse mesmo movimento que considera e legitima apenas uma escala de memória, um chão e seus ícones, reflete no silenciamento de outras histórias, desconsiderando a dimensão relacional na qual os processos históricos se constituem e os modos de viver, sentir e transformar essa mesma cidade, praticados por seus moradores e por sujeitos que para a cidade afluem. À multiplicidade dos espaços sócio-históricos e culturais de Ouro Preto, no tempo, se contrapõe o imperativo de confirmação do dispositivo patrimonial, informando a alguns sujeitos que o "retrato" ideal de Ouro Preto dispensaria o comparecimento de pés descalços, crianças brincando, noivas em pose de álbum, guias turísticos e vendedores ambulantes, privilegiando, por isso, estratégias de conhecimento e experiência da cidade que dispõem em primeiro plano sinhás-moças em passeio e charretes-relíquia como signos da permanência do passado.

Nesse sentido, aponta Paul Ricoeur (2007) que

A ideia chave ligada à ideia de variação de escala é que não são os mesmos encadeamentos que são visíveis quando mudamos de escala ... Ao mudar de escala, não vemos as mesmas coisas, maiores ou menores, em caracteres grandes ou pequenos ... Vemos coisas diferentes. (Ricoeur, 2007, p.221-222)

Assim, quando propomos a variação de escalas para ver e pensar Ouro Preto, entendemos que o ajuste da objetiva, variando das imagens e memórias canônicas de uma cidade-passado a uma cidade-presente (e passados) traria não exatamente a exclusão do passado (não se trata desta operação), mas os jogos de efeito que o devir histórico dispõe ao usufruto dos viventes. Nessa 


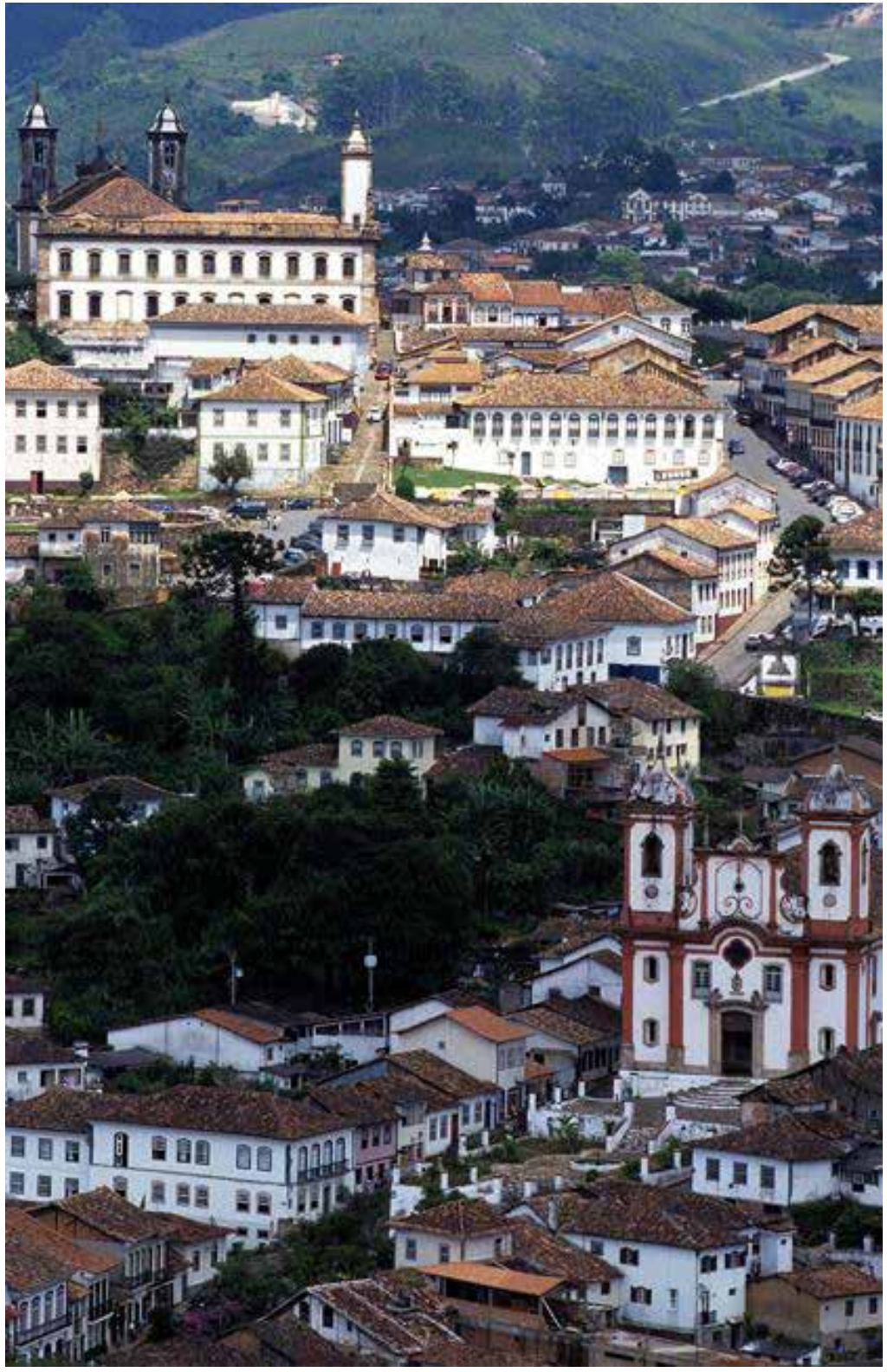

Figura 3 - Panorâmica do centro histórico de Ouro Preto

Imagem disponível em: http://turismo.culturamix.com/nacionais/sudeste/ouro-preto 


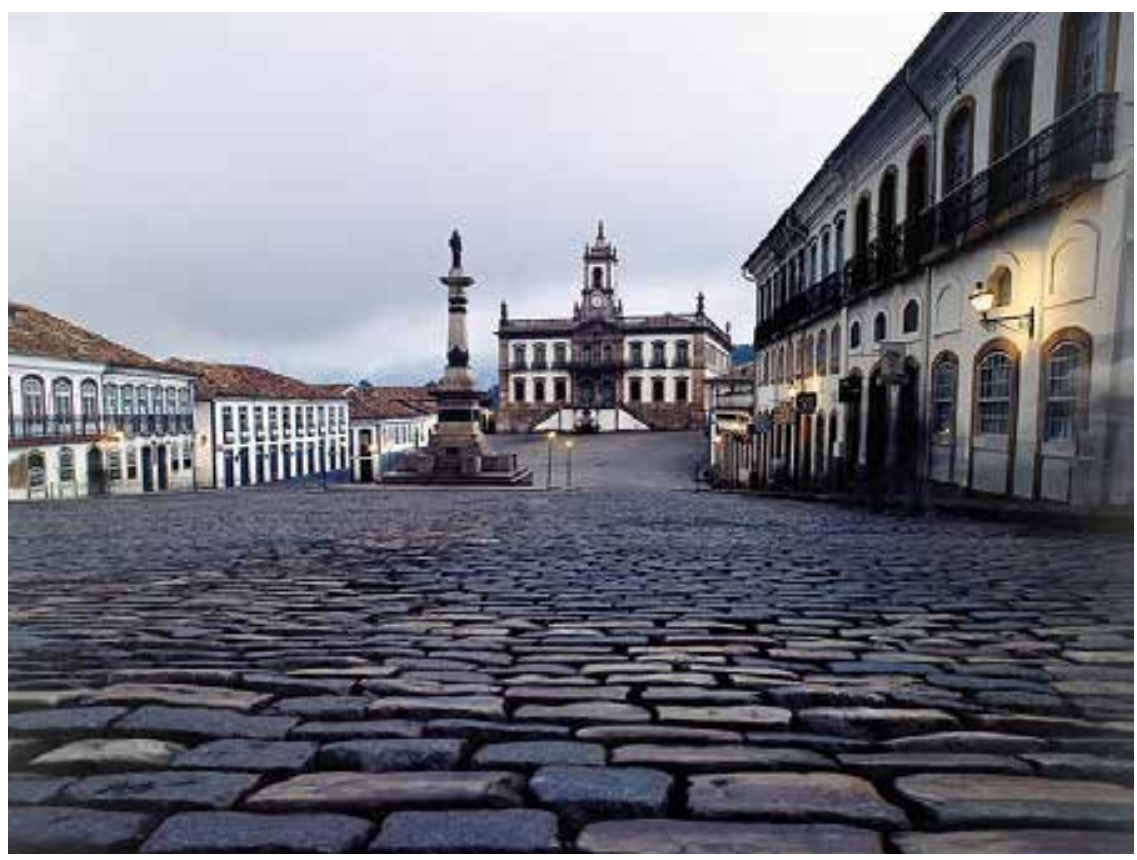

Figura 4 - Centro e Chão Histórico de Ouro Preto - ao fundo, o Museu da Inconfidência

Imagem disponível em: http://turismo.culturamix.com/nacionais/sudeste/ouro-preto

perspectiva o presente inclui o passado, não o elimina. Mas enquanto o passado não coloniza o presente, $o$ interroga.

Pensemos, então, Ouro Preto em uma perspectiva relacional, ajustando o foco sobre as dinâmicas, modos de apropriação do patrimônio e memórias de um dos seus distritos: Miguel Burnier. Com esse exercício desejamos problematizar os efeitos de sentido na relação educativa que podem ser provocados pela subsunção da condição histórica de toda a cidade, ou seja, das várias cidades ouro-pretanas, sendo, por isso, convocadas pelo direito à história tanto quanto o centro patrimonial.

O distrito de Miguel Burnier, com população de 971 habitantes, localiza-se a 40 quilômetros da sede de Ouro Preto e a cerca de 20 quilômetros da sede de Congonhas. Congonhas e Ouro Preto ficaram conhecidas por suas riquezas minerais que remontam ao século XVIII e ao período colonial de maior opulência na região. Ainda hoje a exploração mineral é uma das 
atividades de maior rentabilidade na área, riquíssima em minério de ferro. Mas diferentemente do Ouro, que assegura aos centros históricos de Ouro Preto e Congonhas preservação e tutela sob a égide de uma história legitimada, a exploração do ferro na região provocou não apenas alteração de paisagens naturais, mas também silenciamento de memórias em espaços sócio-históricos e culturais: afinal, a permanência do histórico exige conteúdos dignos de lembrança. O distrito de Miguel Burnier é possivelmente a região de Ouro Preto na qual a exploração de minério de ferro tem interferido, no tempo, de forma mais incisiva, reconfigurando espaços e dinâmicas sociais no decorrer de todo o século XX e de forma mais intensa nestas primeiras décadas do século XXI, quando uma nova indústria siderúrgica passou a explorar e ocupar a região. Para alcançar a parte central do distrito, passando pela rota alternativa a partir da BR-040, é preciso atravessar a guarita da empresa, que sinaliza os limites da exploração.

A formação do atual distrito de Miguel Burnier remonta ao início do século XVIII, quando pequenos povoados foram se estabelecendo às margens do "Caminho Novo", estrada sob controle da Coroa portuguesa que ligava a região das minas ao Rio de Janeiro. De um desses povoados, inicialmente conhecido como Rodeio, depois como São Julião, formou-se o distrito de Miguel Burnier. Rodeio era no século XVIII um ponto de exploração mineral, mas também de passagem e pouso para os demais viajantes.

Findas as reservas auríferas, outras riquezas minerais passaram a ser exploradas na região, dentre elas o minério de ferro. No início do século XIX foi fundada pelo alemão Barão Eschwege a Real Fábrica Patriótica, um dos primeiros empreendimentos siderúrgicos da região. Já em 1887 o Engenheiro Miguel Burnier foi o responsável pela construção da Ferrovia de Miguel Burnier, complexo tombado como patrimônio da cidade pelo Iphan/Ouro Preto pelo decreto $\mathrm{n}^{\circ} 2.468$ de 18 de novembro de 2010. Vale registrar que o movimento em prol do tombamento desse conjunto arquitetônico foi realizado pelo coletivo do Projeto Estação Cultura, ${ }^{3}$ uma iniciativa que desde 2007 tem empreendido esforços junto à comunidade local e ao poder público para reconhecimento, proteção e preservação do patrimônio material e imaterial do distrito. Essa iniciativa foi responsável também pela restauração da Estação Ferroviária que sedia atualmente os projetos culturais desenvolvidos no distrito. 
A linha férrea que passava pelo então povoado de Rodeio foi um importante ponto de conexão entre distritos e municípios de Minas Gerais e do Rio de Janeiro, contribuindo para que as últimas décadas do século XIX e primeiras do XX fossem um período de grande efervescência social e econômica na região. Em 1893 mais uma usina siderúrgica foi inaugurada na região pelo empreendedor Carlos Wigg e pelos engenheiros J. Gerspacher e Amaro da Silveira. As atividades do alto forno da Usina Wigg na região tinham por finalidade o abastecimento da ferrovia de Miguel Burnier e também de seu entorno. Foi através da linha férrea de Miguel Burnier que os trens alimentados pelo ferro da Usina Wigg transferiram mobiliários, documentos, funcionários e histórias da então capital colonial Ouro Preto para a moderna cidade de Belo Horizonte.

A partir de meados do século XX o distrito de Miguel Burnier passou a sofrer os impactos da ampliação da malha viária no Brasil em detrimento da

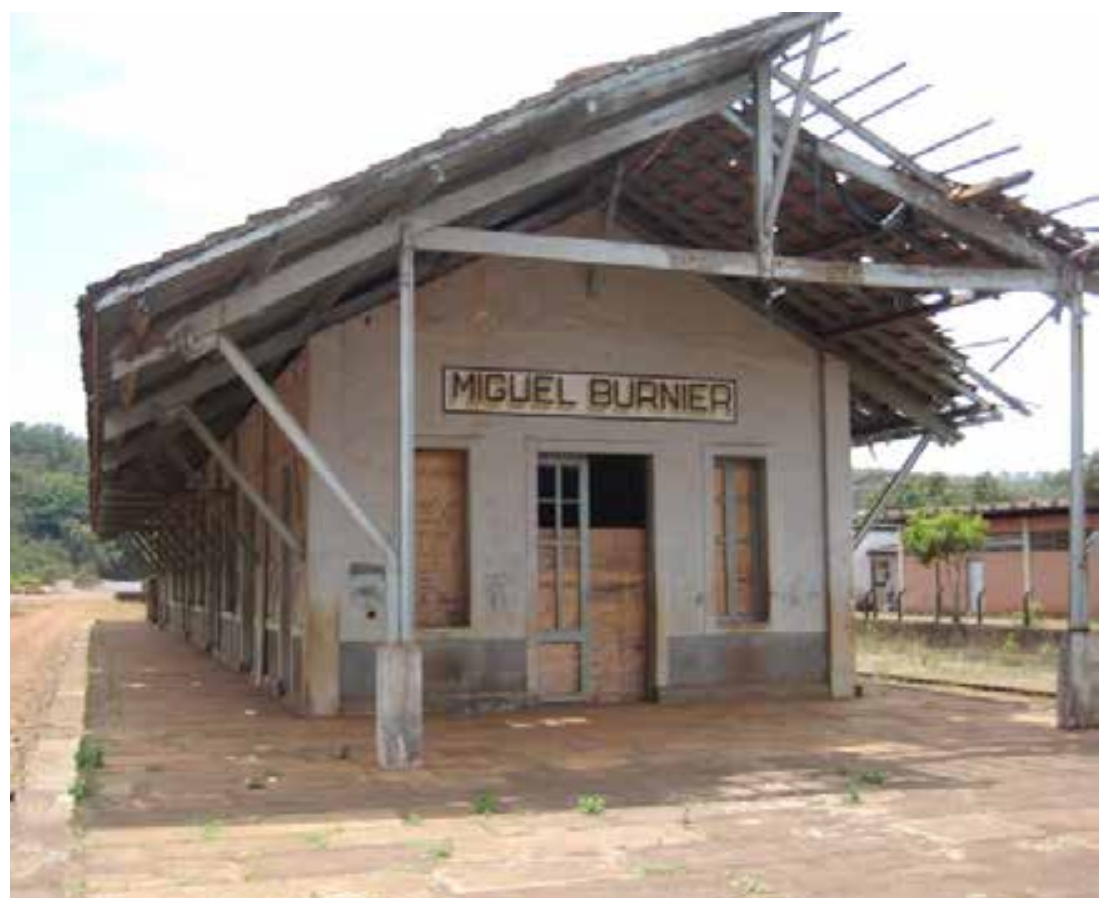

Figura 5 - Estação Ferroviária de Miguel Burnier

Foto de Leandro Menezes, out. 2011. Disponível em: http://www.estacoesferroviarias.com.br/ efcb_mg_linhacentro/burnier.htm 


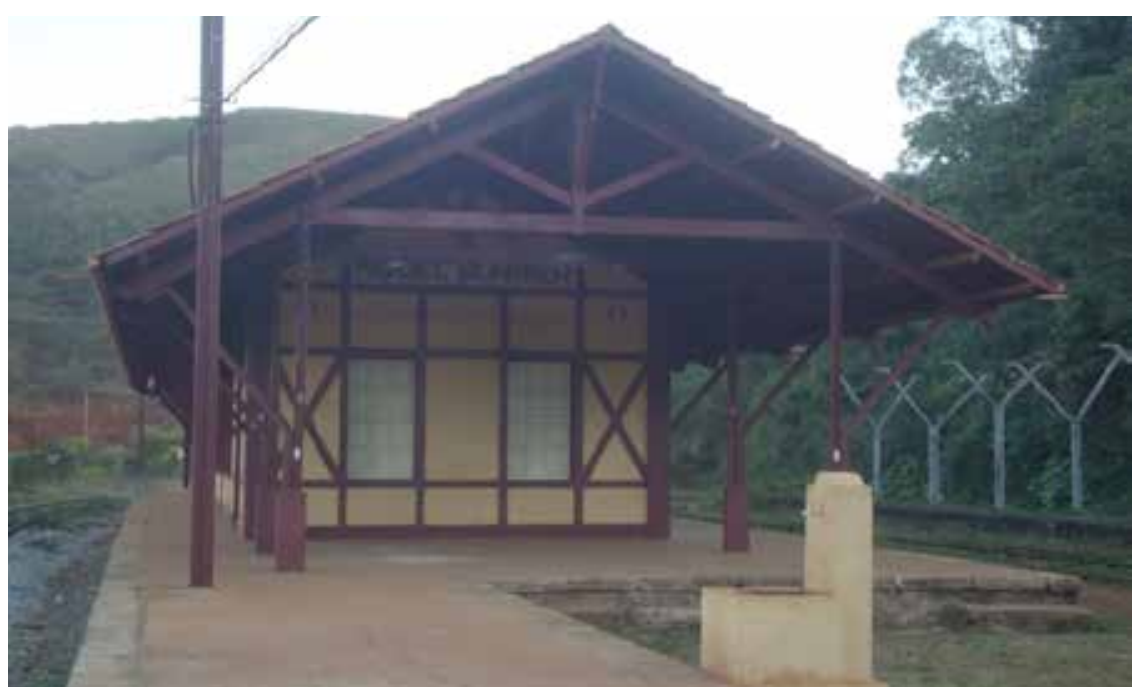

Figura 6 - Estação Ferroviária de Miguel Burnier Foto de Marcel Freitas, jul. 2013, acervo particular

ferroviária. Sem demandas significativas para transporte, a Ferrovia de Miguel Burnier foi desativada no decorrer das décadas de 1980 e 1990, ficando paulatinamente legada ao abandono. Por outro lado, a intensificação da exploração de minério de ferro na região sem os cuidados requeridos com a preservação do espaço sócio-histórico e cultural - de seus bens materiais e imateriais, suas dinâmicas, memórias e histórias, tem conferido a esse distrito de Ouro Preto traços de uma cidade fantasma, na qual persiste apenas um restrito número de moradores - resistindo ou anuindo às condições que lhes são impostas. Do total de 971 habitantes registrados pelo Censo/IBGE de 2010, apenas 382 residem atualmente na área considerada urbana do distrito.

Na contramão desse processo de esquecimento histórico-social do distrito de Miguel Burnier, iniciativas como o Projeto Estação Cultura, citado anteriormente, idealizado e gerido por Marco Antônio de Almeida Costa desde 2007, têm empreendido esforços na tentativa de manter significativos os laços culturais, históricos e sociais dessa comunidade. Uma das principais ações do projeto foi a restauração da Estação Ferroviária de Miguel Burnier, finalizada em 2012, a qual de marca do abandono passou a figurar como centro de manifestações culturais regionais, dentre elas a Festa dos Burnienses Ausentes, 


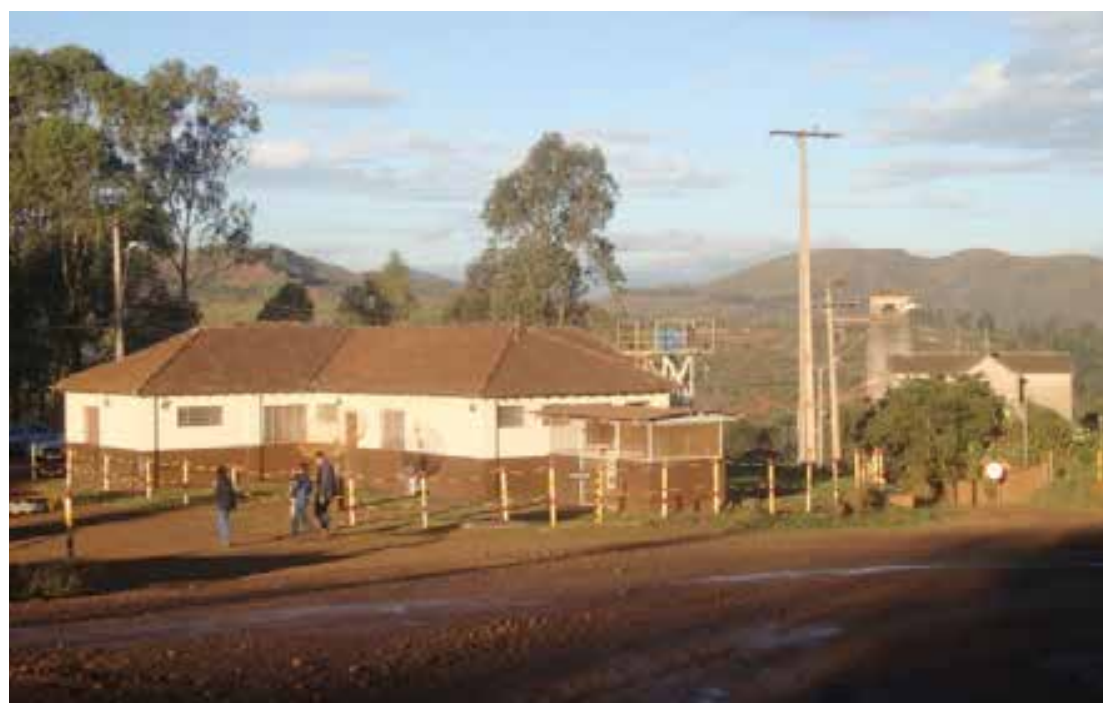

Figura 7 - Distrito de Miguel Burnier. Em primeiro plano a estação da indústria siderúrgica que atualmente explora a região, e ao fundo a Igreja do Sagrado Coração

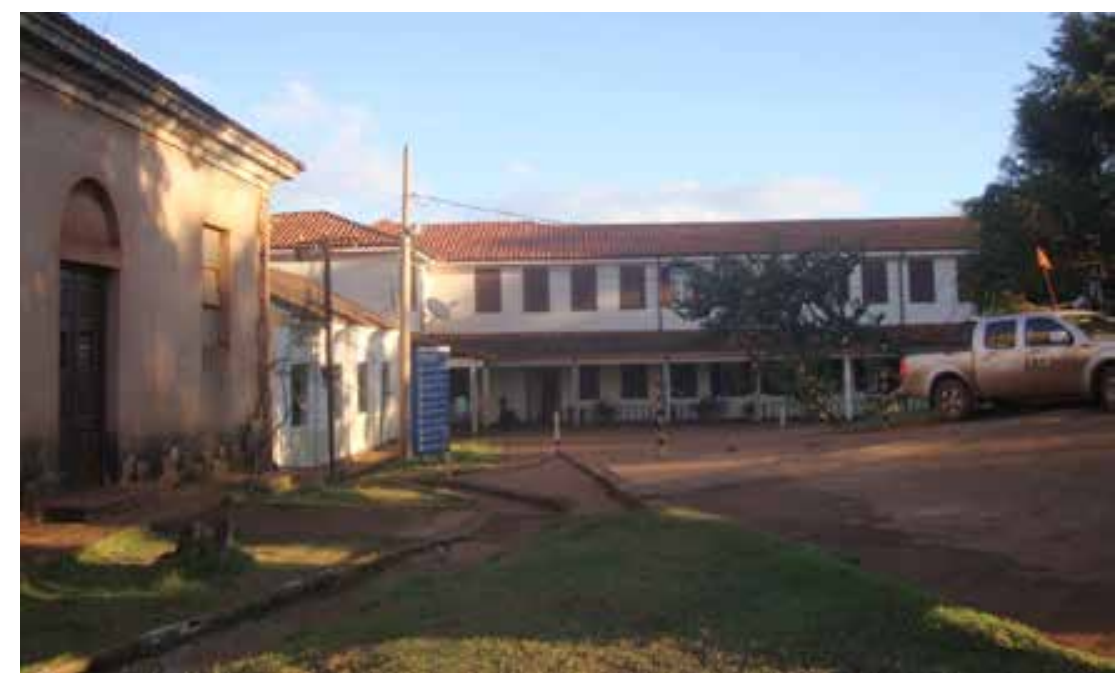

Figura 8 - O antigo Convento, anexo à Igreja do Sagrado Coração, foi restaurado pela indústria siderúrgica e serve como sede administrativa da empresa na região 


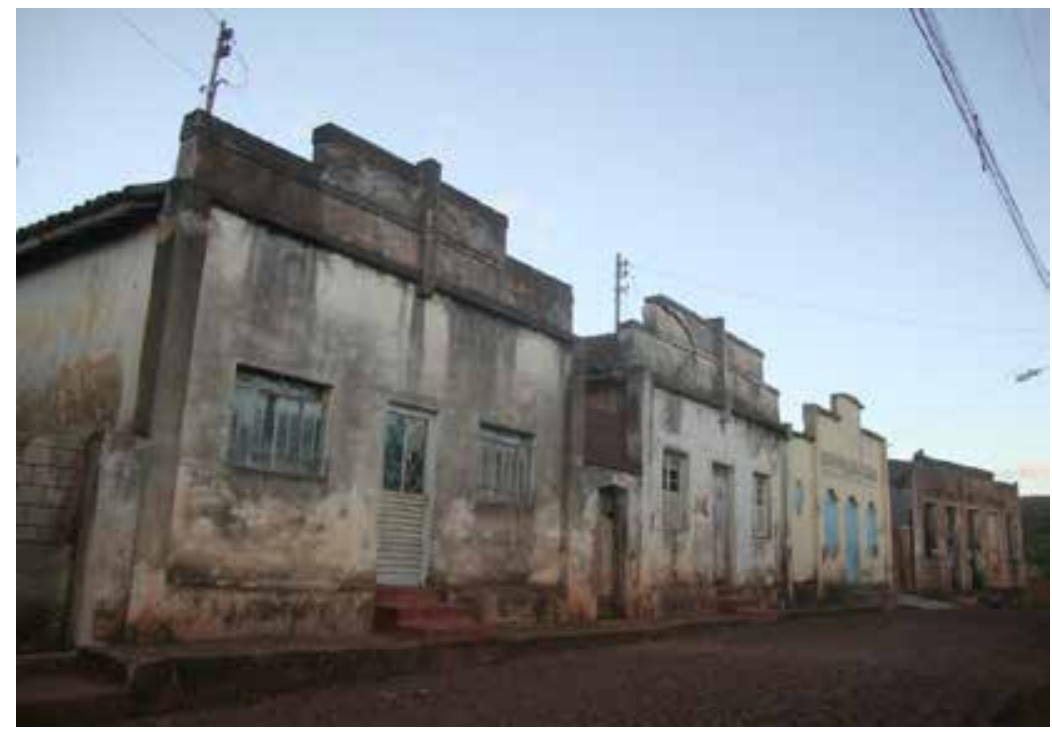

Figura 9 - Entorno da linha férrea, próximo à Estação de Miguel Burnier

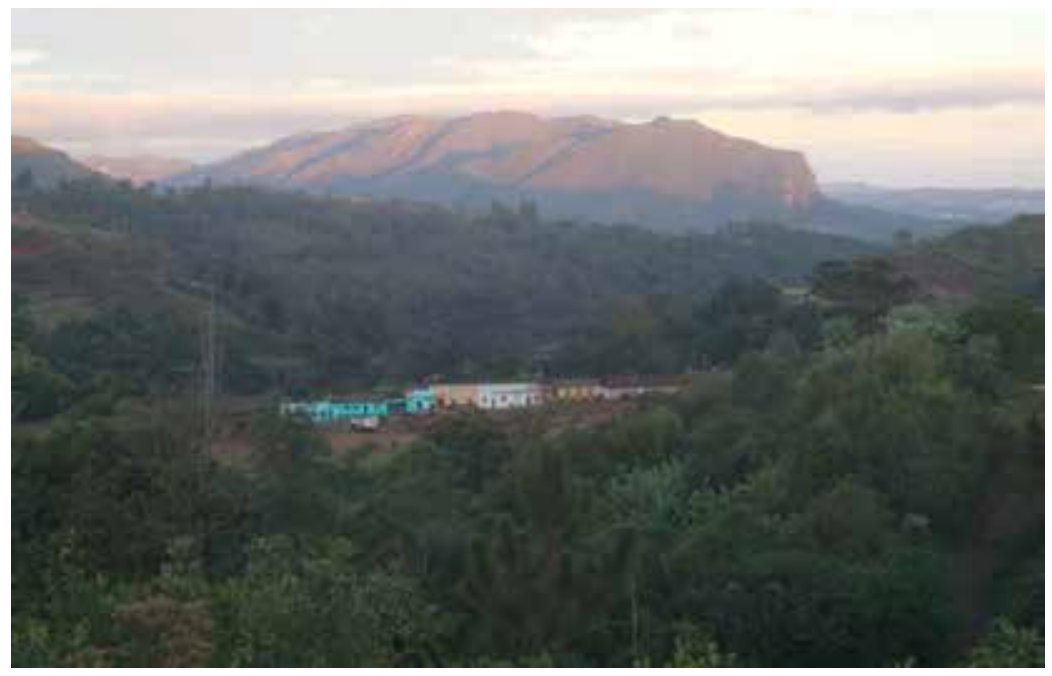

Figura 10 - Vista panorâmica do entorno da Estação Ferroviária

Fotos de Marcel Freitas, jul. 2013, acervo particular 
realizada anualmente entre fim de junho e início de julho. O mesmo projeto realiza anualmente o Festival Cultural de Ouro Preto (em 2013 ocorreu a $5^{\text {a }}$ edição), em um movimento pelas memórias e manifestações culturais do distrito. Iniciativas como estas indicam como os viventes históricos nos diferentes cenários de Ouro Preto buscam de dentro para fora agitar memórias silenciadas pelas barreiras simbólicas legitimadas neste contexto específico.

A consideração ao histórico no processo vivencial de uma cidade produz, assim, miríades de efeitos de sentido aos moradores e a quem as visita. Mas, sobretudo aos moradores, porque vivem dinâmicas paradoxais, costurando memórias silenciadas àquelas destacadas como condições da história da humanidade, perfazendo a premência da lembrança aos reclames patrimoniais. A experiência sócio-histórica dos viventes de uma cidade dividida pelo patrimônio não pode ser ignorada em aulas de história, sob pena de priorização de um efeito de sentido e não dos vários tantos efeitos que a lembrança produz ao reclamar as suas permanências. Uma cidade cindida pelas razões da história, em que estão opostos ou até contrapostos o centro e os demais distritos, proporcionará certamente em abordagens educativas o despertar de sensibilidades para entendimento da costura da história sob dispositivos das lutas com que se realizou a demarcação do esquecimento. Uma cidade multiplicada sob chão patrimonial ideal ou sob todos os solos da história: eis o limiar da atuação docente, aquele que pode ser alargado fazendo ver os distritos fantasmas ou mesmo os fantasmas que parcimoniosamente passeiam pelo centro em noite de lua cheia.

Sem desconsiderar a importância das políticas públicas de patrimonialização principalmente para o reconhecimento, a preservação e a divulgação de bens culturais de natureza material e imaterial, o que nos interessa aqui é provocar reflexões sobre os seus efeitos de sentido em aulas de história, evidenciando escalas possíveis para compreensão e alargamento dos horizontes de interpretação deste espaço múltiplo que é o de uma cidade "histórica". Enquanto nos preocupamos em demasiado com a preservação do reclame de uma identidade mineira em grande parte vinculada ao período colonial, à sua opulência aurífera e à cultura barroca, desviamos a atenção - e os cuidados para que outras histórias e suas memórias sejam conhecidas, fazendo habitar os solos nos quais aqueles que estão vivos produzem o real-histórico. 
Compreendemos que os caminhos históricos para o apreender $\mathrm{da} / \mathrm{na}$ cidade são trilhados pelos sujeitos, guiados por suas vivências e percepções. São, ademais, orientados por razões históricas. Interrogamo-nos acerca dos efeitos da patrimonialização, atentas tanto à enunciação de sentidos quanto à evocação de silenciamentos: afinal, com quantas histórias se faz a história de uma cidade? Que efeitos de conhecimento se produzem quando em uma mesma cidade há marcos considerados mais históricos do que outros? Que horizontes de pertencimento se produzem em cenários de patrimonialização? De que forma alargar as visadas interpretativas com vistas a proporcionar o conhecimento e a experiência sensível dos sujeitos em cenários que opõem presente e passado em jogos dissonantes? Em qual e por meio de qual escala o histórico é definido?

Ademais, os fundamentos que conferem legitimidade ao histórico em cidades como Ouro Preto se articulam àqueles gerados pela patrimonialização, fazendo aflorar o impensado do tempo: um centro histórico da humanidade, no qual do chão aos sons dos sinos tudo é patrimônio, tudo é afeto ao passado, tudo é histórico. O limite físico e simbólico da autenticidade do histórico em cidades históricas como Ouro Preto coincide com o da demarcação do centro, tornando periféricas as zonas fronteiriças, os distritos e os marcos simbólicos que, pouco ou nada informados pelo marco colonial, se secundarizam em face da amplificação que o legítimo direito ao usufruto da cultura pela humanidade se impõe diante da cidade-relíquia mundial.

Nessa operação de confecção do histórico estão presentes o conteúdo colonial marcado pela longevidade e pela opulência e o conteúdo material evidenciado pela arquitetura e estrutura física da cidade-sede. Estão da mesma forma operantes os conteúdos atribuídos à função da cidade na história de Minas e, por extensão histórica, de Minas como semióforo da nação. Além disso, o conteúdo barroco como condição histórica - em que materialidade e experiência inegavelmente se evidenciam - materializa Ouro Preto como uma cidade para historiadores (Hartog, 2006), uma cidade-aula, constituindo a subsunção da relevância história dos demais registros, no jogo do tempo, que realizaram essa mesma cidade. Os efeitos da cidade colonial se perpetuam nos tempos por meio de encenações, ações preservacionistas com vistas à permanência dos registros e marcos arquitetônicos, e, mais, por meio dos modos de viver e de usufruto cultural. 
As inquirições acerca dos limites de constituição da condição histórica dispõem possibilidades interpretativas em aulas de história capazes de proporcionar a elucidação dos jogos temporais que, em dados momentos, singularizaram áreas e temporalidades como mais históricas ou como autenticamente históricas em oposição a outras. No refinado jogo que dispôs os tempos desenhando a face relíquia do passado colonial brasileiro as peças do decurso histórico foram estrategicamente periferizadas, provocando a convivência não harmônica entre vários cenários patrimonializados porque hierarquizados.

Assim, na hierarquia patrimonial a disposição de primeira linha conferida ao barroco ouro-pretano suscita em aulas de história a percepção das ressonâncias do patrimônio nos modos de vida, convocando a uma educação informada por processos intersubjetivos em que mais do que a autenticidade do histórico objetiva-se a experiência sensível da multiplicidade de relações simbólicas que delineiam o histórico de uma cidade. A univocidade do patrimônio colonial amplifica-se, assim, com a vida em curso num jogo de temporalidades e por meio da presença do sentido da história fractalizada pelos variados registros patrimoniais e significativos que concretizaram a Ouro Preto de todos os tempos.

\section{REFERÊNCIAS}

ABDALA, Mônica Chaves. Receita de mineiridade: a cozinha e a construção da imagem do mineiro. Uberlândia, MG: Ed. UFU, 1997.

ARRUDA, Maria Arminda do Nascimento. Mitologia da mineiridade: o imaginário mineiro na vida política e cultural do Brasil. São Paulo: Brasiliense, 1990. . O mito da mineiridade. Tese (Doutorado) - FFLCH, USP. São Paulo, 1987.

BAETA, Alenice; PILÓ, Henrique. Marcas Históricas Miguel Burnier - Ouro Preto. Belo Horizonte: Gerdau, 2012.

BECHLER, Rosiane Ribeiro. Minas Gerais em jogos de escalas: variações do conhecimento histórico escolar em livros didáticos regionais. Dissertação (Mestrado) FAE, UFMG: Belo Horizonte, 2014.

CAMPOS, Fernando Rogério de Lima. Miguel Burnier: o lugar da fragmentação. Monografia (TCC) - UFMG. Conselheiro Lafaiete, 2012.

DA MATTA, Roberto. Nação e região: sobre o significado cultural de uma permanen- 
te dualidade brasileira. In: SCHLEE, Aldyr Garcia; SCHÜLER, Fernando Luis; DA GLÓRIA BORDINI, Maria. Cultura e identidade regional. Porto Alegre: Ed. PUCRS, 2004.

DULCI, Otávio Soares. As elites mineiras e a conciliação: a mineiridade como ideologia. Ciências Sociais Hoje, p.7-32, 1984.

FRIEIRO, Eduardo. Feijão, angu e couve: ensaio sobre a comida dos mineiros. (v.72). Belo Horizonte: Itatiaia, 1982.

HALL, Stuart. A identidade cultural na pós-modernidade. Rio de Janeiro: DP\&A, 2011.

HARTOG, François. Tempo e Patrimônio. Varia Historia, Belo Horizonte, v.22, n.36, p.261-273, jul.-dez. 2006.

. Regimes de historicidade: presentismo e experiências do tempo. Belo Horizonte: Autêntica, 2013.

HOBSBAWM, Eric; RANGER, Terence (Org.) A invenção das tradições. Rio de Janeiro: Paz e Terra, 1984.

MORAIS, Luciana Patrícia de. Culinária típica e identidade regional: a expressão dos processos de construção, reprodução e reinvenção da mineiridade em livros e restaurantes de comida mineira. Dissertação (Mestrado) - Faculdade de Filosofia e Ciências Humanas, UFMG. Belo Horizonte, 2004.

NORA, Pierre. Entre memória e história: a problemática dos lugares. Projeto História. (Revista do Programa de Estudos Pós-Graduados de História, São Paulo: PUC, v.10, 1993.

OLIVEIRA, Rodrigo Francisco de. Mil tons de Minas: Milton Nascimento e o Clube da Esquina: cultura, resistência e mineiridade na música popular brasileira. Dissertação (Mestrado) - Universidade Federal de Uberlândia. Uberlândia, MG, 2006.

REVEL, Jacques. Jogos de escalas: a experiência da micro-análise. Rio de Janeiro: Ed. FGV, 1998.

RICOEUR, Paul. A memória, a história, o esquecimento. Trad. Alain François. Campinas, SP: Ed. Unicamp, 2008.

ROCHA, Simone Maria. Identidade regional, produção e recepção: A "mineiridade" na televisão. In: CONGRESSO NACIONAL DE PÓS-GRADUAÇÃO EM COMUNICAÇÃO - COMPÓS, 12. Recife, PE, 2003.

SILVA, Marcos A. da. Republica em migalhas: historia regional e local. São Paulo: Marco Zero; MCT/CNPq, 1990.

VAINFAS, Ronaldo. Os protagonistas anônimos da História.: micro-história. Rio de Janeiro: Campus, 2002. 


\section{NOTAS}

${ }^{1}$ Sobre a discussão ver: DA MATTA, 2004.

${ }^{2}$ Sobre o assunto ver: ABDALA, 1997; DULCI, 1984; FRIEIRO, 1982; MORAIS, 2004; OLIVEIRA, 2006; ROCHA, 2003, dentre outros.

${ }^{3}$ Sobre o projeto visitar a página http://projetoestacao.blogspot.com.br/.

Artigo recebido em 24 de setembro de 2014. Aprovado em 23 de outubro de 2014. 